\title{
ParalOQRde!?
}

\section{OS (DES)CAMINHOS DA GEOGRAFIA AGRÁRIA BRASILEIRA: A INVISIBILIZAÇÃO DO NEGRO NOS ESPAÇOS RURAIS BRASILEIROS}

\author{
The (dis)ways of brazilian agrarian geography: the invisibilization of black people in \\ brasilian rural spaces
}

\author{
Aline da Fonseca Sá e Silveira \\ Professora do curso de Licenciatura em Geografia - UEMG \\ silveira_geo@yahoo.com.br
}

\begin{abstract}
Recebido em 27/06/2019. Aceito para publicação em 30/07/2019.
Versão online publicada em 10/09/2019 (http://seer.ufrgs.br/paraonde)
\end{abstract}

\begin{abstract}
Resumo:
A fim de se compreender a ausência do protagonismo da população negra nos estudos agrários brasileiros, o presente trabalho tem por objetivo trazer à tona algumas reflexões acerca da produção teórica realizada no Brasil, no período entre os anos de 1934 e 1960 - denominado Geografia Agrária Clássica ou Tradicional -, bem como avaliar as políticas de branqueamento populacional e científico, assim como a sua interface com a criação dos primeiros cursos de Geografia no país. Dessa maneira, buscou-se sistematizar parte dos estudos sobre a formação do espaço agrário brasileiro, com o objetivo principal de se compreender a ausência do negro como sujeito social nos estudos dos fenômenos agrários e apontar para considerações equivocadas relativas ao contingente negro nos espaços rurais brasileiros.
\end{abstract}

Palavras-chave: Geografia Agrária Brasileira; Negro; Invisibilização do negro; Geografia Agrária Clássica; Espaço rural brasileiro.

\begin{abstract}
:
In order to understand the lack of protagonism of the black population in Brazilian agrarian studies, this paper aims to bring to light some reflections about the theoretical production carried out in Brazil, in the period between 1934 and 1960 - called Classical Agrarian Geography or Traditional - as well as to evaluate the policies of population and scientific laundering, as well as its interface with the creation of the first geography courses in the country. In this way, we sought to systematize part of the studies on the formation of Brazilian agrarian space, with the main objective of understanding the absence of the black as a social subject in the studies of agrarian phenomena and pointing to misconceptions regarding the black contingent in Brazilian rural spaces.
\end{abstract}

Key-words: Brazilian agrarian geography; black people; Invisibilization of the black people; Classical agrarian geography; Brazilian rural area.

\section{Introdução}

O presente trabalho visa compreender a ausência da população negra, como sujeitos protagonistas de suas histórias, sob a perspectiva da Geografia Agrária Brasileira. O passado escravocrata e o elevado contingente populacional negro nos campos nos incita a pensar o(s) porquê(s) de uma população negra tão invisibilizada, 
que levam-nos a crer em campesinatos homogeneizadores e em termos cunhados numa Europa também diversa, mas que se propõe universalizante.

Sendo assim, a presente análise restringe-se aos estudos de geografia agrária brasileira constituídos entre os anos de 1934 e 1960 - denominado de Geografia Agrária Clássica ou Geografia Agrária Tradicional - que, para nós, devem ser encarados como de extrema relevância para a compreensão, construção e amadurecimento deste subcampo de análise, visto que os trabalhos produzidos neste período apresentam-se como esteios para o desdobramento de estudos futuros. Tal recorte temporal, permitenos rememorar a importância das Escolas Francesa e Alemã na constituição do pensamento geográfico brasileiro, uma vez que a criação dos primeiros cursos superiores em Geografia no Brasil (Universidade de São Paulo, em 1933 e Universidade do Distrito Federal, no Rio de Janeiro, em 1934) se deu graças aos esforços de geógrafos franceses que tiveram importância vultuosa na estruturação e manutenção do curso; assim como as principais pesquisas elaboradas por instituições como o Conselho Nacional de Geografia (CNG) e, posteriormente, o Instituto Brasileiro de Geografia e Estatística (IBGE), que tiveram suas bases epistemológicas fundamentadas, também, na escola de pensamento alemã.

Acredita-se que a ausência de estudos acerca da escravização da mão de obra negra no Brasil se deve ao momento histórico vivido pelos países europeus do início do século XX que não tinham o interesse em compreender os impactos e as consequências do sistema político-econômico escravagista, principalmente no que se refere a população negra. Ao contrário, a França dos séculos XIX e XX estava voltada para a compreensão das transformações advindas do sistema político-ideológico capitalista, sob o "respaldo" de teorias fundamentadas em ideais eugenistas e perspectivas racialistas para explicar suas ações imperialistas no continente africano e também no Novo Mundo. Em outras palavras, os estudos realizados sobre os espaços rurais brasileiros, sob a perspectiva francesa da primeira metade do século $X X$, não contemplaram os negros como sujeitos e descaracterizaram suas práticas e contribuições - seja em âmbito rural, seja em espaços urbanizados - em prol de uma Ciência eurocêntrica, descrevendo o branco europeu como o principal agente promotor do colonato no Brasil.

Da mesma maneira, observa-se a ausência dos estudos geográficos no período pré-abolicionista pelos representantes da Escola Alemã e seus sucessores. As pesquisas realizadas sob a perspectiva corológica, de diferenciação de áreas, das paisagens culturais e nas formações econômicas das paisagens agrárias foram executadas com o objetivo de compreender as transformações advindas com a colonização europeia dos últimos anos do século XIX e o uso das terras agricultáveis em áreas de expansão e com déficits populacionais, ignorando todas e quaisquer contribuições promovidas pela população negra rural, seja aquela mantida na condição de cativa ou como liberta.

Em arremate a esta problemática, destacam-se que os estudos precursores da Geografia Agrária no Brasil dar-se-ão sob uma perspectiva eugenista, debruçando-se muito pouco na compreensão do contingente populacional negro e suas transformações nos espaços rurais brasileiros, sendo os negros elencados apenas em tons pejorativos, subestimando suas habilidades e práticas culturais, invisibilizando os inúmeros atos de resistência negra e desassociando-os como responsáveis por promover e manter o Brasil como uma das principais potências agroexportadoras do mundo, desde o período 
colonial até os dias de hoje.

\section{A constituição da Geografia Agrária Brasileira}

A constituição da geografia agrária brasileira passa, obrigatoriamente, assim como os demais subcampos de análise de nossa ciência, pela formação dos primeiros cursos superiores em Geografia. A universidade no Brasil se dá a partir dos alinhamentos teóricos vetorizados em continente europeu e que chegam em solo nacional configurando os contornos do campo disciplinar geográfico, já que as universidades assumem papel central na produção do(s) saber(es).

Em paralelo à importância das universidades para a construção do arcabouço teórico e a transmissão do conhecimento produzido, destaca-se, em igual importância, a produção realizada nos demais institutos de pesquisa nos quais a ciência geográfica sustentou (e ainda sustenta) os estudos elaborados. Estes, por sua vez, também se constituíram a partir de influências europeias e por conseguinte é possível reconhecer essas características ainda nos dias de hoje.

Os dois pilares, a criação dos cursos superiores em Geografia e o fomento dos centros de pesquisa em nossa área, ainda na década de 1930, amparam, de maneira geral, toda produção da geografia agrária brasileira, entretanto, o que até então não foi contemplado em meio a esse debate, são os inúmeros acontecimentos que ocorrem em paralelo a esses eventos: a política de criação de uma identidade nacional, bem como a consolidação do mito da democracia racial, através da obra de Gilberto Freyre, permearão todo esse momento de nascimento da Geografia Brasileira e, sem dúvidas, deixarão suas marcas em toda a produção nacional.

\section{a. As transformações políticas da virada do século $X X$ : a abolição da mão de obra escrava negra, a política de branqueamento populacional e o mito da democracia racial}

As duas maiores transformações vividas pelos brasileiros na virada do século XX são a abolição da mão de obra escrava negra (1888) e a proclamação da República (1889) que serão o estopim para os câmbios que se alongarão até meados do século $X X$. $O$ Brasil, do início do século, vive uma tentativa de modernização que passa, obrigatoriamente, pela construção de uma identidade nacional - tornar-se república e "aberta" às transformações advindas com o avanço do sistema capitalista, e consequentemente ao processo de urbanização e reestruturação produtiva nos campos, demandou a edificação de uma identidade nacional.

Numa perspectiva bastante abrangente, é possível afirmar que os teóricos da virada do século teciam suas produções baseados naquilo que era produzido na Europa do século XIX, pois além de suas formações terem acontecido neste continente, este será considerado o berço da produção científica. Neste período, as teorias de Comte, Darwin e Spencer borbulhavam e extravasavam para diversas partes do mundo, principalmente para o Novo Mundo. Nesse interim, tais produções que tem como o evolucionismo histórico dos povos o seu aspecto comum, os teóricos e literatos brasileiros terão como sustentáculo a mesma premissa evolucionista. Em outras palavras, o Brasil será considerado atrasado, em relação aos países europeus, em virtude de sua elevada 
miscigenação.

A compreensão desse atraso seria justificada a partir da raça e do meio. "Na realidade, meio e raça se constituíam em categorias do conhecimento que definiam o quadro interpretativo da realidade brasileira" e base argumentativa para legitimar a economia escravagista, a brutalidade e sexualidade do mulato, a apatia do mameluco, entre tantos outros exemplos pejorativos sobre os ditos "sujeitos de cor" (ORTIZ, 1985, p. 16). Para Sílvio Romero, um dos fundadores das Ciências Sociais no Brasil, o fator racial é o mais problemático e abrangente, já que a raça deve ser lida como a base fundamental da estrutura social, da história e, consequentemente, da política, estética e moral das nações.

Para Renato Ortiz, a única alternativa para a população brasileira do início do século XX reconhecer-se com unidade foi a construção da identidade nacional a partir do mestiço, no entanto, para garantir a evolução social e a construção de um Estado nacional é preciso pensar num projeto efetivo de branqueamento populacional. $O$ que se ventilava desde meados do século XIX, efetivou-se logo após a Abolição, mais precisamente em 1890 - a política nacional de branqueamento populacional.

A ideia do projeto de branqueamento era bastante simples: tornar a população brasileira totalmente branca, bem próxima dos padrões europeus, entretanto, para atingir esse objetivo, precisava-se diminuir gradualmente o seu contingente populacional negro, o que era encarado como algo natural pelos eugenistas, pois afirmava-se que estes apresentavam baixa taxa de natalidade, elevados números de óbito por doenças contagiosas e não havia organização social por parte desses grupos. Sendo assim, o número de negros diminuiria gradualmente, enquanto 0 contingente populacional branco, mais forte e inteligente, teria melhores condições de elevar em números absolutos e percentuais.

Aliado a este processo, incentivou-se que as pessoas de cor (negros e mulatos) buscassem se relacionar com parceiros mais claros, e para que este procedimento fosse possível, afim de atender a demanda existente, promoveu-se a entrada de imigrantes europeus que possibilitariam esse branqueamento, em termos percentuais, imediato e também a longo prazo, através dos casamentos promovidos entre as partes. O quadro intitulado "Redenção de Can", do espanhol erradicado no Brasil, Modesto Brocos (1895), representa de forma sintética e elucidativa o resultado do projeto de branqueamento. Ao longo de um século de desenvolvimento e ação do projeto, o país tornar-se-ia branco, assim como a criança representada na tela a seguir (Fig. 1). 


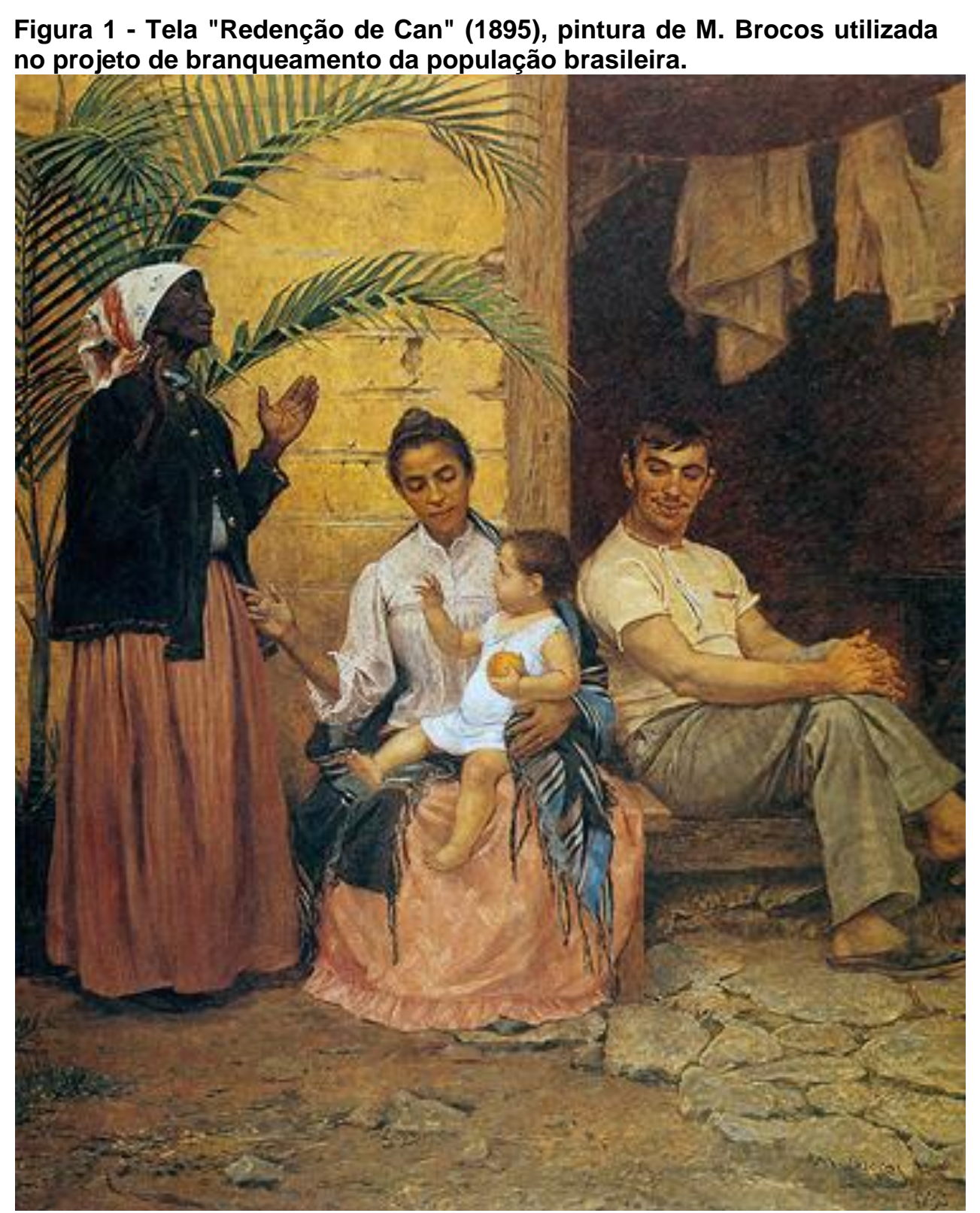

Fonte: Museu de Belas Artes, Rio de Janeiro.

A imagem retrata o país como uma nação de raças distintas e miscigenadas, mas numa certa transição em relação ao gradiente de cor entre as gerações representadas. Como pode ser observado, há quatro sujeitos que compõem o cenário proposto por Brocos: uma mulher negra, com traços africanos fortemente marcados, mas de vestimentas características da população portuguesa dos séculos XVIII-XIX. Essa mesma mulher - a avó negra -, que parece agradecer aos céus pela representação da cena que se coloca à sua frente, apresenta-se de pés descalços sobre o chão de terra e trajando roupas humildes, o que leva ao observador ao entendimento de se tratar de uma pessoa muito simples, sem posses, e que neste ato se coloca a contemplar sua filha, já miscigenada e de pele mais clara, com roupas melhores que as suas e numa espécie de transição entre o chão de terra e o calçamento. A criança que carrega em seu colo apresenta a tonalidade da pele ainda mais clara que a da mãe, bem próxima, ou equivalente, a de seu pai - o único homem representado na tela. Este homem branco, que nos leva a crer ser o genro dessa avó, encontra-se sentado e calçado sobre o chão 
de pedras; sua postura, em relação à cena, o impede de enxergar a avó, mas ainda contempla a mesma cena: a mãe (provavelmente sua esposa) e o seu filho. Em outras palavras, o observador da tela de Brocos é impelido a pensar que o cruzamento das raças, negra africana e o branco europeu, levaria ao seu branqueamento ao longo de um século.

No campo jurídico, tal política pode ser constatada a partir de 1890, dois anos após a Abolição da mão de obra escrava, através do Decreto 528, de 28 de Junho de 1890, que regulariza o serviço de introdução e localização de imigrantes no Brasil, como pode ser observado a seguir:

\section{DECRETO 528, DE 28 DE JUNHO DE 1890}

\section{CAPITULO I - DA INTRODUCÇÃO DE IMMIGRANTES}

Art. $1^{\circ} \mathrm{E}$ ' inteiramente livre a entrada, nos portos da Republica, dos individuos válidos e aptos para o trabalho, que não se acharem sujeitos á acção criminal do seu paiz, exceptuados os indigenas da Asia, ou da Africa que sómente mediante autorização do Congresso Nacional poderão ser admittidos de accordo com as condições que forem então estipuladas.

Art. $2^{\circ}$ Os agentes diplomaticos e consulares dos Estados Unidos do Brazil obstarão pelos meios a seu alcance a vinda dos immigrantes daquelles continentes, communicando immediatamente ao Governo Federal pelo telegrapho quando não o puderem evitar.

Art. $3^{\circ}$ A policia dos portos da Republica impedirá o desembarque de taes individuos, bem como dos mendigos e indigentes.

Art. $4^{\circ}$ Os commandantes dos paquetes que trouxerem os individuos a que se referem os artigos precedentes ficam sujeitos a uma multa de 2:000\$ a 5:000\$, perdendo os privilegios de que gozarem, nos casos de reincidencia.

O decreto garantia o livre acesso aos portos brasileiros, desde que os imigrantes não fossem indígenas da Ásia ou da África, e aqueles que permitissem a entrada dos povos restringidos sofreriam penalizações e multas elevadas em caso de reincidência. Essa proposição será assegurada, mais uma vez, em 1945, através do Decreto-Lei № 7.967 de 18 de Setembro, que dispõe sobre a imigração e colonização e dá outras providências, com especial destaque para o artigo 2, do Capítulo 1 - admissão:

Art. 1ํ Todo estrangeiro poderá, entrar no Brasil desde que satisfaça as condições estabelecidas por esta lei.

Art. 2ํㅡㄹ Atender-se-á, na admissão dos imigrantes, à necessidade de preservar e desenvolver, na composição étnica da população, as características mais convenientes da sua ascendência européia, assim como a defesa do trabalhador nacional.

Os exemplos jurídicos elencados permitem afirmar que a ideologia do branqueamento obteve aparato legal, efetivou-se por mais de meio século e, contraditoriamente, foi escamoteada pela afirmação de uma democracia racial sustentada pela criação da identidade nacional em torno do mestiço.

\section{b. A consituição dos cursos superiores em Geografia e a institucionalização de uma ciência eugenista}

A constituição do curso superior em Geografia baseou-se no modelo francês, materializado na contratação de professores deste país que tiveram a responsabilidade de não apenas lecionar, mas de pensar a estrutura do curso, trazendo ainda mais as 
características de seus precursores. Pierre Deffontaines foi o primeiro catedrático de Geografia na USP, articulou e organizou a formação do curso superior em Geografia e a fundação da AGB, em sua breve passagem pelo Brasil (1934 e 1936-37). Apesar de sua curta permanência, Deffontaines "deixou um legado organizacional e de cunho teóricometodológico fundamental para a consolidação disciplinar nas décadas seguintes no Brasil" (SOUSA, 2015).

O cenário atribulado dos anos 1930 teve repercussão na obra deste autor que, enquanto ideólogo de uma visão liberal e atento às contribuições da época, retratou a concepção da democratização das raças no Brasil e ainda manteve presente em seus trabalhos muitos atributos das teorias eugenistas, adaptando sua forma de geografar as regiões brasileiras de acordo com suas particularidades. Uma análise mais cuidadosa sobre sua obra se faz pertinente, não apenas para uma reflexão acerca da constituição da Geografia Agrária, mas para compreender como se deu a base teóricoepistemológica que alicerça a Geografia Brasileira e quais as consequências desses embasamentos para as reflexões atuais.

Para exemplificar a afirmação apresentada, destaca-se a obra "Os Indivíduos-Tipos do Brasil", escrita em 1936 (publicada na Revista Boletim Geográfico, no ano de 1947) e baseada no argumento elaborado pelos geógrafos funcionalistas-culturais que utilizavam como recurso investigativo os "tipos humanos". Os tipos humanos são os estudos realizados para a compreensão de sociedades complexas, onde os gêneros de vida não são aplicáveis em virtude da sua limitação operacional - os gêneros de vida foram pensados para estudar sociedades simples e organizações tribais, desprovidas de estratificações e classes sociais. No caso brasileiro, foi preciso utilizar-se dos indivíduostipos em virtude da grande complexidade da sociedade do século XX. Sendo assim, cada indivíduo-tipo expressaria o seu gênero de vida e este, por sua vez, seria o responsável por deixar as marcas na paisagem.

Os indivíduos-tipos do Brasil, apresentados por Deffontaines (1947) foram os:

- fazendeiros, o tipo dominante e mais antigo;

- colonos, aqueles sujeitos que gravitam em torno dos fazendeiros, tratam-se dos operários contratados pelos fazendeiros;

- vendedores ambulantes, também conhecidos como mascates. Os primeiros foram os baianos que vislumbraram na hinterland brasileira um horizonte de trabalho;

- mestiços (ou caboclos), constituídos por elementos que vivem à margem da população organizada dos campos; e

- caiçaras, são os mestiços que vivem ao longo do litoral atlântico e passam a ser pescadores. Sua subsistência é baseada na exploração da floresta e do mar.

Ao longo do texto, os sujeitos negros e indígenas são mencionados apenas para explicar quem eram os mestiços, mas não são compreendidos como um tipo-indivíduo. Acredita-se que o autor faça o esforço de encarar a identidade nacional através do mestiço, no entanto, suas caracterizações são pejorativas no trato desses sujeitos e, por vezes, sugere o branqueamento da população a fim de que se realize melhor seu desenvolvimento físico e intelectual. Ao apresentar os fazendeiros, por exemplo, o autor se remete aos índios da costa como 
[...] habituados a uma economia de simples colheita, sem dispensar verdadeiro esforço, não puderam suportar o regime de trabalho que se lhes impunha nas plantações. Praticaram o que se chamou cinicamente de "a greve da morte"; com efeito, foi, na verdade, a densidade do trabalho que os europeus têm o hábito de suportar e de impor que provocou uma imensa hecatombe nas populações indígenas (1947, p. 140).

O apontamento extremamente preconceituoso de Deffontaines não os coloca (os índios) como indivíduos-sujeitos, apenas como uma mão de obra inadaptável que implicará em problemas de acomodação do agricultor português. Já a população negra sequer é citada. Os escravos são abordados para explicar a espacialidade da fazenda plantation e para indicar que a supressão da escravidão não transformou o regime da fazenda, na verdade, os escravos com a Abolição dão lugar aos colonos que terão, na visão do autor, proximidade e confiança nos contratos de meia e nos tratos comerciais.

Percebe-se, ao longo deste texto e de tantos outros, que Deffontaines analisa o Brasil sob uma perspectiva eugenista e colonial, retratando os sujeitos mestiços - a nova identidade nacional brasileira - de maneira negativa e sugere, inclusive, que o branqueamento da população é uma campanha idealizada para deter o rebaixamento da raça promovido com a caboclização dos colonos dos Espírito Santo e São Paulo. E, ainda assim, conclui seu ensaio afirmando que os diversos indivíduos-tipos e demais elementos, dentre eles os mais evoluídos e os mais primitivos, vivem em singular associação e coexistem em perfeita harmonia. Ou seja, para o autor, ainda que o Brasil apresente todas essas heterogeneidades, vive-se em harmonia social e sem quaisquer tipos de problemas raciais, salvo aqueles apresentados pelo rebaixamento das raças nas uniões estabelecidas entre europeus e negros/indígenas.

É neste contexto em que as universidades e as associações, aliadas à Ciência Geográfica, foram estruturadas no Brasil.

Deffontaines retorna à França no final de 1934 deixando como seu sucessor o jovem Pierre Monbeig, discípulo de Albert Damageon e propagador das bases metodológicas de Vidal de La Blache. Monbeig esteve no Brasil de 1935 à 1946, período em que se dedicou verticalmente à vida acadêmica, publicou diversos livros e obteve subsídios para defender sua premiada tese de doutorado "Planteurs et pionniers dans l'Etat de Saint Paulo" na Sorbonne, em 1950.

Os estudos desenvolvidos por Monbeig terão inestimável importância para a Geografia Agrária Brasileira, pois debruçou-se sobre essa temática e desenvolveu contribuições pioneiras sobre a expansão cafeeira no interior de São Paulo e Paraná, a partir de temas ligados aos gêneros de vida numa perspectiva regional, com especial enfoque à compreensão do habitat rural, além de trabalhar sob a análise comparativa entre diferentes regiões, já que, para o autor, a comparação é uma excelente ferramenta para desenvolver ideias em estudos já conhecidos.

A temporalidade, contudo, pode ser questionada na obra de Monbeig, não por sua ausência, mas por sua parcialidade. Toma-se como exemplo, suas "Notas relativas à evolução das paisagens rurais no estado de São Paulo", Monbeig ignora completamente os elementos históricos anteriores à política de imigração europeia. Ou seja, as paisagens rurais, assim como o habitat rural da região, são consideradas apenas no pós Abolição, invisibilizando milhares de sujeitos responsáveis pela manutenção daquela cultura (neste caso, o café) tão cara aos estudos de Monbeig. O texto, de rápidas considerações, aponta que a região de Franca, norte do estado de São Paulo, e Vitória, 
capital do estado do Espírito Santo, podem enfim "receber e ver prosperar colonos brancos, de origem mediterrânea ou eslava" (1944, p. 428) e acrescenta, em suas considerações finais, que "as paisagens rurais testemunham uma melhor utilização do solo" (idem, p. 430). Relevante seria apontar que Vitória e Vila Velha, no Espírito Santo, foram importantes pontos de chegada de mão de obra negra escravizada da África, ademais, a afirmação de que é possível perceber uma melhor utilização do solo remete, obrigatoriamente, a uma comparação de tempos distintos. Entretanto, o autor não se preocupa em identificar esse tempo pretérito, o que é encarado como uma tentativa de invisibilizar os sujeitos responsáveis pela agricultura antes da chegada dos imigrantes europeus, bem como as diferenças abissais entre a mão de obra negra escravizada (desumanizada) e os trabalhadores rurais de procedência europeia e seus descendentes.

Em sua principal obra, Pioneiros e Fazendeiros de São Paulo, Monbeig aponta para algumas singularidades entre os fazendeiros e as diferentes mãos de obra utilizadas:

Com espírito assim tão moderno, perfeitamente a par das realizações, enfrentaram os grandes fazendeiros o problema da mão-de-obra. Não cabe em nosso assunto, nem é de nossa competência, estudar o considerável problema da abolição da escravatura. Seus aspectos políticos, seu lado sentimental prenderam já a atenção dos historiadores, e não deixaram os melhores dentre eles de assinalar as relações entre o desaparecimento do regime servil e o desenvolvimento da cultura cafeeira. Indispensável é, todavia, dizer como o problema foi colocado e compreendido entre os fazendeiros (Ibidem, p. 101).

É notório que, para Monbeig, a abolição da escravatura é considerada um problema, mas a atenção dos geógrafos não deve estar voltada aos aspectos políticos e aos sentimentos envolvidos nesse processo (contrariando sua própria ideia de complexo geográfico), o que deve ser feito, então, é entender como o problema foi encarado e contornado pelos fazendeiros - o notável protagonista dessa história, de acordo com o autor em debate.

Deffontaines e Monbeig deixaram, além de um legado teórico inquestionável, alguns discípulos de seus estudos que merecem a mesma atenção, mas que em virtude de nossas limitações serão analisados de maneira abrangente, são eles: Caio Prado Jr., Ary França, Nice Lecocq Müller, Orlando Valverde, Walter Egler, Lysia Bernardes e Nilo Bernardes. As inúmeras obras escritas por tais geógrafos pátrios estão atreladas teórica e metodologicamente aos seus sucessores e terão uma característica em comum que nos desperta atenção: a invisibilização do negro nos estudos rurais ou seu entendimento a partir de uma categoria homogeneizadora, depreciativa e incapaz de identificar as particularidades vividas pelo contingente populacional negro no campo brasileiro. Ademais, é possível notar certa reprodução de uma mentalidade colonial, eurocêntrica, eugenista e despreocupada em compreender as transformações socioespaciais protagonizadas pela população negra nos espaços rurais brasileiros. Detivemo-nos entre esses autores por acreditar que podem ser encarados como os alicerces dos estudos em Geografia Agrária no Brasil, respaldando, assim, os trabalhos subsequentes. As consequências de se não questionar o protagonismo negro nos espaços rurais é observar nos estudos contemporâneos traços dessas adversidades e ausências que, como já sinalizamos, podem ser as responsáveis por uma compreensão parcial, ou distante da realidade dos espaços rurais no Brasil.

Os geógrafos pátrios apontados acima debruçaram-se sobre as transformações 
advindas com as grandes imigrações europeias, datadas com maior expressão entre os anos de 1870 à 1895, ou seja, não tiveram a preocupação de compreender os mais de 3 séculos iniciais da colonização brasileira - àqueles onde a mão de obra escrava negra foi massivamente utilizada -, o que demonstra a clara intenção de invisibilizar a importância do negros na formação do espaço rural brasileiro e, ainda, em forjar a concepção de um colonato europeu. Dentre os geógrafos brasileiros, destacamos Walter Egler que, num breve momento que trata da produção relativa à população negra, descreve que seus métodos agrícolas são atrasados e levam ao esgotamento do solo. Contudo, os imigrantes europeus se valeram das técnicas já utilizadas pelos negros, pois, em virtude de suas condições econômicas, não tinham como introduzir os métodos mais aperfeiçoados de seu país de origem, como no trecho destacado a seguir:

$\mathrm{E}$, assim, o imigrante europeu, em lugar de introduzir os métodos mais aperfeiçoados de seu país de origem, adota os processos usuais no Brasil, porque os mesmos se enquadram em ambiente econômico em nosso interior. É preciso não generalizar, porém, pois em algumas regiões, onde agrupamentos numerosos se localizaram em pontos onde havia facilidade de transporte e garantia de mercados, a sua situação manteve-se mais estável e métodos mais racionais são empregados. A grande massa, porém, emprega o sistema conhecido por "rotação de terras" (EGLER, 1992, p. 57).

O que se pode perceber diante desse trecho é que as queimadas e a rotação de terras eram técnicas possíveis diante da estrutura disponível no interior do país. No entanto, a compreensão do atraso condicional se dá quando o autor remete às práticas realizadas pelos imigrantes que ali se fixaram, mas não aos negros e índios que também têm de enfrentar as limitações locacionais, dentre outros problemas que não atingem o colono europeu. O que não se coloca nesta análise, e que para nós é de indispensável importância, é que os imigrantes europeus, ao contrário dos negros, índios e mestiços, receberam pequenas propriedades do governo e outros subsídios que facilitariam sua produção quando comparado aos demais grupos citados. Sendo assim, os imigrantes teriam maiores e melhores condições de implementar técnicas mais elaboradas em suas propriedades, no entanto o que se observou foi a replicação daquilo que era comumente versado por aqueles que já realizavam a prática agrícola de consumo próprio - os índios, negros e mestiços.

O que também se pretende destacar na obra de Egler é sua crítica referente aos subsídios oferecidos à parte dos imigrantes que, de acordo com o autor, é como um auxílio mútuo e deve ser realizado a fim de dar condições mais apropriadas para a produção de gêneros alimentícios e tornar viável a colonização.

\footnotetext{
Um outro esforço bem dirigido e pouco conhecido no restante do Brasil vem sendo realizado pelo Estado da Bahia no sentido de aproveitar racionalmente os imigrantes. Só no período de 1949/50 entraram no Estado mais de 500 imigrantes, entre agricultores, trabalhadores industriais, etc. $\mathrm{Na}$ localização dos colonos dos núcleos coloniais agrícolas o governo estadual dispende cerca de 80 mil cruzeiros com cada família, fornecendo-lhes tudo, desde a casa de morada até a semente para plantar. Os resultados têm sido à altura das expectativas [...].

Tudo isto demonstra que para obter resultados positivos na imigração não basta simplesmente trazer o alienígena e deixa-lo entregue à sorte. A colonização tem de ser um contrato mútuo (Idem, p. 68).
}

A partir do trecho destacado acima, fica claro, portanto, que mesmo os imigrantes, considerados mais esclarecidos que os índios e negros que já trabalhavam na terra, necessitavam de auxílios para que a colonização fosse exitosa. Mais uma vez, identificase a ausência das populações residentes no espaço rural brasileiro como àquelas que também poderiam se beneficiar dos auxílios destinados à produção de gêneros alimentícios. 
O que se propõe aqui é ratificar que a exclusão dos negros e mestiços de uma política que visava apoiar e dar condições de acesso à terra, melhoria do solo, mecanização da lavoura e apoio ao cooperativismo fez parte de uma outra política - a do branqueamento populacional - e, por isso, esse contingente (de não europeus) não poderia ser contemplado pelo pacote de apoio aos pequenos proprietários de terra. Em primeiro lugar, porque negros não tinham acesso à compra da terra ${ }^{1}$, e, em segundo lugar, porque o objetivo da época era o de branquear a população, isso era evidente como pudemos ver nos decretos-Lei destacados no início do capítulo. De certa forma, o projeto foi exitoso, mas não em sua completude. A população embranqueceu e os estudos invisibilizaram os negros por mais de 60 anos (1888-1950). Na Geografia essa invisibilização durou ainda mais, visto que o primeiro trabalho de pós-graduação que abarcou a questão negra data dos anos finais do século XX, mais precisamente em 1998, com Andrelino Campos, com sua dissertação de mestrado que, posteriormente, deu origem ao livro Do Quilombo à Favela: a produção do "espaço criminalizado" no Rio de Janeiro, cuja primeira edição foi lançada em 2004.

\section{Considerações Finais}

A Lei de Terras de 1850 e a Política de Branqueamento Populacional - que, como vimos, estendeu-se para o campo político e científico - foram, de certa maneira, exitosas, pois a dificuldade ao acesso à terra e a não absorção da mão de obra negra no pós-Abolição inviabilizaram a permanência do contingente negro nos campos. É sabido, todavia, que foram diversas as alternativas criadas por grupos de resistência negra nos espaços rurais brasileiros, tendo o quilombo a sua manifestação mais eloquente e duradoura (no tempo-espaço), contudo, seus estudos e notoriedade alçarão espaços na Geografia Agrária Brasileira, apenas no início dos anos 2000, com os pesquisadores do período Agrário Social.

Apesar de não termos tido a pretensão de elaborar uma crítica ao período denominado Agrário Social, é importante destacar que a não ruptura com o constructo teórico do período Agrário Tradicional, tratado brevemente neste artigo, evidencia o continuum de ideias geradas nas primeiras décadas da institucionalização de nossa Ciência. Em outras palavras, a invisibilização da população negra como agente transformadora do espaço rural brasileiro no período tradicional da Geografia Agrária alicerçou concepções, ao nosso ver, equivocadas dos protagonistas dos campos brasileiros, bem como sua atuação pretigiosa no setor econcômico - mais uma consequência da política de branqueamento populacional que extrapola os limites da cor do povo brasileiro.

O que nos desperta certa inquietação referente a tais políticas é que elas foram determinantes na constituição da Ciência Geográfica no Brasil, devidamente invisibilizadas pelos precursores da Geografia (Agrária) brasileira e imortalizadas através da produção e reprodução de suas concepções. Sugere-se, portanto, que tal subcampo de análise seja revisto e debatido com o devido cuidado, a fim de evidenciar as particularidades de diversos grupos negros que constituíram o maior contingente populacional no Brasil ao longo de mais de quatro séculos e que há milhares de anos têm na agricultura a base de sua concepção de sujeito-comunidade.

\footnotetext{
1 Para melhor compreensão do tema, ver Lei de Terras, de 1850.
} 


\section{Referências}

CAMPOS, Andrelino. Do quilombo à favela: a produção do "espaço criminalizado" no Rio de Janeiro. $3^{\mathrm{a}}$ edição - Rio de Janeiro: Bertrand Brasil, 2010.

DEFFONTAINES, Pierre. A População Branca no Brasil. Boletim Geográfico. Ano III, n. 32, p. 1069-1071, 1945. 140-147, 1947.

Os Indivíduos-Tipos e Aspectos do Brasil. Boletim Geográfico. Ano V, n. 50, p.

EGLER, Walter. Problemas agrários do Brasil. Boletim Carioca de Geografia. Rio de Janeiro, 4 (2-4), 1951.

. Coletâneas de Trabalhos de Walter Augusto Egler. Belém: Museu Paraense Emilio Goeldi, 1992.

MONBEIG, Pierre. Notas relativas à evolução das paisagens rurais no Estado de São Paulo. Boletim Geográfico, ano 2, n. 16, p.428-430, 1944.

. Pioneiros e Fazendeiros de São Paulo. São Paulo: Editora HUCITEC e Editora POLIS, 1984 (1950).

ORTIZ, Renato. Cultura Brasileira e Identidade Nacional. São Paulo: Editora Brasiliense, 1985.

SILVA, Simone R. A trajetória do negro no Brasil e a territorialização quilombola. Revista NERA. Presidente Prudente, ano 14, №19, jul-dez/2011, p. 73-99.

SILVEIRA, Aline F.S. Quilombo Santana: seus conflitos e o processo de desterritorialização da comunidade quilombola, município de Quatis - RJ. 2014. 153 f. Dissertação (Mestrado em Geografia), - Universidade do Estado do Rio de Janeiro PPGEO/UERJ, Rio de Janeiro, 2014.

SILVEIRA, Aline F.S. \& MELO, Emerson. Quilombola: uma identidade em construção ou aplicação de um conceito? In: XXIII Encontro Nacional de Geografia Agrária. Anais... São Cristóvão, 2016.

SOUSA, André N. Percurso Historiográfico do Campo Disciplinar Geográfico na Bahia e em São Paulo: contribuições da Universidade Federal da Bahia e da Universidade de São Paulo. Tese (Doutorado em Geografia) - Universidade Federal da Bahia, Salvador, 2015. 